\title{
A strengthening theory to prevent fatigue crack initiation in old metallic bridges
}

Conference Paper · June 2016

CITATIONS

READS

0

7 authors, including:

\section{Elyas Ghafoori}

Empa - Swiss Federal Laboratories for Materi... 36 PUBLICATIONS 390 CITATIONS

SEE PROFILE

\section{Xiao-Ling Zhao}

Monash University (Australia)

429 PUBLICATIONS 5,705 CITATIONS

SEE PROFILE

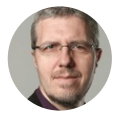

École Polytechnique Fédérale de Lausanne

148 PUBLICATIONS 705 CITATIONS

SEE PROFILE

Gary S. Prinz

University of Arkansas

24 PUBLICATIONS 131 CITATIONS

SEE PROFILE

Some of the authors of this publication are also working on these related projects: 


\title{
A strengthening theory to prevent fatigue crack initiation in old metallic bridges
}

\author{
E. Ghafoori \& M. Motavalli \\ Empa, Swiss Federal Laboratories for Materials Science and Technology, Dübendorf, Switzerland
}

A. Nussbaumer

EPFL, Swiss Federal Institute of Technology Lausanne, Steel Structure Laboratory, Lausanne, Switzerland

X.L. Zhao

Monash University, Department of Civil Engineering, Clayton, Victoria, Australia

A. Herwig

Engineering Office Conzett Bronzini Partner AG, Chur, Switzerland

M. Fontana

ETH Zurich, Institute of Structural Engineering, Zurich, Switzerland

G.S. Prinz

University of Arkansas, Department of Civil Engineering, Fayetteville, AR, USA

ABSTRACT: Analytical solutions were developed to determine the fatigue resistance of metallic members retrofitted by bonded carbon fiber-reinforced polymer (CFRP) laminates. Different fatigue failure criteria based on the constant life diagram (CLD) approach were introduced to predict the strengthening properties that would prevent fatigue cracks in metallic members. The use of normal modulus (NM), high modulus (HM) and ultra-high modulus (UHM) CFRP laminates with different pre-stress levels was considered in the modeling. To validate the model, a series of fatigue experiments were performed on four steel beams strengthened with bonded NM, HM and UHM CFRP laminates. The results have shown that there are two main mechanisms that can transition the detail from a risky finite-life regime to a safe infinite-life regime. In particular, UHM laminates have been shown to be effective to prevent fatigue crack initiation in steel members. In this paper bonded CFRP laminates were used for strengthening, however, the method can be applied for other retrofit elements such as un-bonded laminates, bolted steel plates and pre-stressed steel tendons.

\section{INTRODUCTION}

Metallic Members are often designed on the basis of a 'safe-life'. The 'safe-life' is essentially the lifetime to initiation of fatigue cracks. Fatigue cracks may initiate when the 'safe-life' of the metallic member has been exceeded. Once fatigue cracks are initiated, they often grow rapidly. Maintenance of such members in service once a fatigue crack has initiated would require short inspection intervals that can be uneconomic, especially if the member is inaccessible. On the other hand, when a nominally sound metallic member reaches its 'safe-life', it has to be either replaced or strengthened, although no obvious cracks or fatigue damage may be present. Rather than replacing the entire bridge or member, retrofit solutions to extend the member 'safe-life' are recommended.

\subsection{Strengthening with composite materials}

The conventional method of repairing or strengthening aging steel structures often involves bulky and heavy plates that are difficult to fix and are prone to corrosion of their own. Furthermore, welding additional steel plates to a metallic bridge often creates cracks at the weld toes in heat affected zone (HAZ) due to inability for welding or poor weldability of such steels (because of containing too much sulfur, for example). It has been shown (Akesson 1994, AlEmrani and Kliger 2006, Colombi et al. 2003a, Colombi et al. 2003b, Dawood et al. 2007, Deng et al. 2004, Denton 12-14, December 2001, El-Hacha and Aly 2013, Ghafoori 2013, Ghafoori and Motavalli 2013, Haghani et al. 2009, Kim and Harries 2011, Nozaka et al. 2005, Rizkalla et al. 2008, Saadatmanesh et al. 1989, Schnerch et al. 2006, Schnerch and Rizkalla 2008, Tavakkolizadeh and Saadatmanesh 2003, Wu et al. 2013a, Wu et al. 2013b) that an advanced material called carbon fiber-reinforced polymer (CFRP) has great potential to enhance steel structures in terms of increased strength, ductility, energy absorption and fatigue life.

\subsection{Strengthening with bonded and un-bonded CFRP laminates}

There are research studies that have shown the efficiency of CFRP strengthening for fatigue strengthening of metallic members, however, in practice, CFRP strengthening has not experienced many advances in the realm of metallic structures compared with those for concrete structures. There might be several reasons for such limited use of CFRP strengthening in practice. One reason can be related 
to the long-term performance of the CFRP-to-steel bonded joints. Many research studies have raised concerns regarding the effects of environmental conditions and dynamic loadings on the bonded joints. It has been shown that environmental conditions, such as ultraviolet light, elevated or subzero temperatures, moisture and water, as well as dynamic loadings, such as impacts, earthquakes and fatigue, can affect the performance of CFRP-to-steel bonded joints (Wu et al. 2013b, Zhao 2013, Zhao et al. 2014, Zhao and Zhang 2007). Because of the concerns related to CFRP-to-steel bond join, recently, un-bonded CFRP retrofit systems have been used for strengthening of steel elements (Ghafoori 2015). Strengthening using the un-bonded systems does not require surface preparation of the metallic substrate, which reduces the overall time of onsite retrofitting. A series of experiments have been performed to compare the flexural performance of metallic beams strengthened by bonded and un-bonded CFRP laminates (Ghafoori and Motavalli 2015b, Ghafoori and Motavalli 2015c). Riveted girders in 120-year-old historic railway bridge in Switzerland were strengthened using a pre-stressed un-bonded reinforcement (PUR) system and monitored using a wireless sensor network (WSN) system (Ghafoori and Motavalli 2015a, Ghafoori et al. 2014).

\subsection{A proactive fatigue design approach}

As mentioned earlier, there are many studies on fatigue strengthening using CFRP materials (e.g., Colombi et al. (2003a), Täljsten et al. (2009), Wu et al. (2013a)), however nearly all of these studies have used CFRP for strengthening 'cracked' steel members to reduce or arrest fatigue crack growth (FCG). In this type of studies, the assessed steel specimens typically had a pre-crack of a certain crack length, which simulated the presence of a real crack. The results of such studies have shown that CFRP could reduce the FCG rate by reducing the overall stress intensity factor (SIF) at the crack tip, which could lead to a longer fatigue life. In other studies, the overall SIF at the crack tip was reduced to below threshold SIF generated by the pre-stressed CFRP laminates. Note that the concept of the threshold SIF is normally used in damage-tolerant designs and defines the loading criterion under which the cracks grow negligibly.

The concept of the fatigue limit, which is the focus of this paper, is often used in the fatigue resistance design approach and determines the loading criterion under which no cracks form. Ghafoori et al. (2015b), Ghafoori et al. (2015a) and Ghafoori (2015) developed a method based on the fatigue resistance design approach, and determined the minimum CFRP pre-stress level required to prevent fatigue crack initiation. It was theoretically and experimentally demonstrated that by applying a compressive force to a metallic detail using a pre-stressed CFRP laminate, the stresses can be shifted below the fatigue limit so that no cracks will form. In this paper, a closed-form analytical solution was developed to predict the stresses in the beams strengthened by the pre-stressed CFRP laminates. Different mechanisms by which the stresses were shifted from the risky 'finite-life' region to the safe 'infinite-life' region are explained. The results of the analytical solution are compared with the results of a series of static and fatigue experiments.

\section{BACKGROUND THEORY}

\subsection{Proposed fatigue design criteria}

The CLD methodology is a method that uses the combined effect of alternating stress, mean stress and material properties (see Fig. 1) to predict the material life-time under high-cycle fatigue. For a given maximum stress $\left(\sigma_{\max }\right)$ and minimum stress $\left(\sigma_{\min }\right)$ in a sample stress history, the stress amplitude $\left(\sigma_{\mathrm{a}}\right)$ and the mean stress $\left(\sigma_{\mathrm{m}}\right)$ can be demonstrated in a CLD plot as shown in Figure 2.

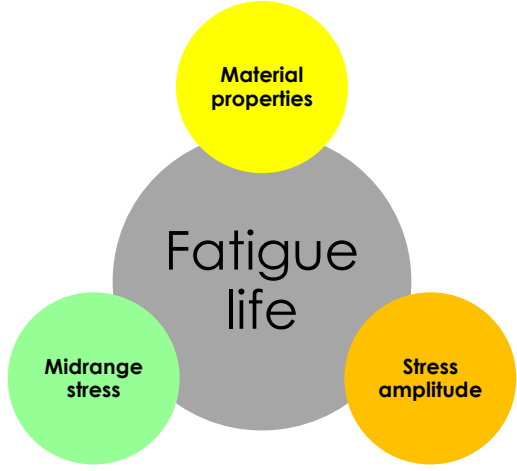

Figure 1. Fatigue life of metals is a function of material properties, midrange stress level and stress amplitude level.

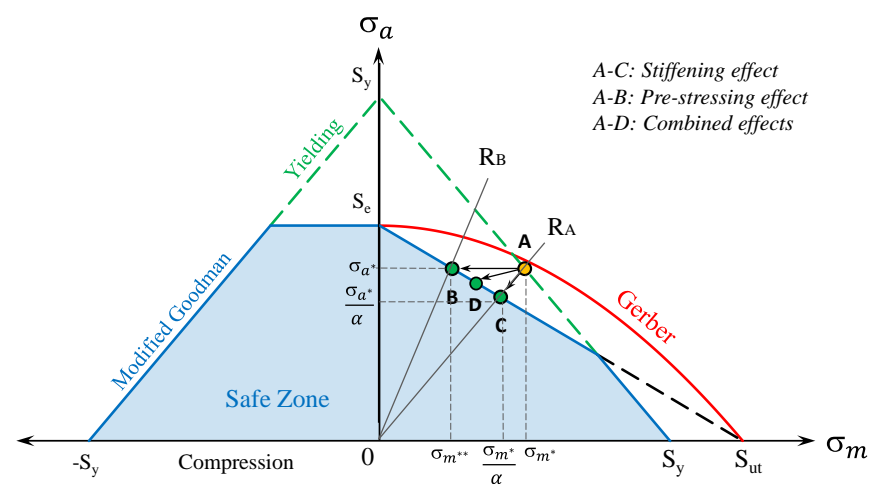

Figure 2. Different retrofitting scenarios: shifting the stresses at the critical locations from the risky to the safe region through the A-B path, the A-C path or the A-D path (Ghafoori 2015).

The right region bounded by $\mathrm{R}=1$ and $\mathrm{R}=0$ is for tension-tension $(\mathrm{T}-\mathrm{T})$ stresses, the middle region bounded by $\mathrm{R}=0$ and $\mathrm{R}= \pm \infty$ is for tensioncompression (T-C) stresses and the left region bounded by $\mathrm{R}= \pm \infty$ and horizontal axis is for com- 
pression-compression (C-C) stresses. The level of the fatigue failure probability has also been schematically illustrated by different markers. The green triangle marker shows the safe zone, in which no cracks will form. The yellow square marker indicates the risky zone, where cracks may form with approximately a 50\% probability. The red circular marker shows the unsafe region, where cracks will form with a probability of more than $50 \%$.

Based on extensive experimental analysis, Goodman proposed a straight line through $\sigma_{a}=\mathrm{S}_{\mathrm{e}}$ and $\sigma_{m}=\mathrm{S}_{\mathrm{ut}}$, with criterion equation (Budynas and Nisbett 2008):

$\frac{\sigma_{a}}{S_{e}}+\frac{\sigma_{m}}{S_{u t}}=\frac{1}{n}$

where $S_{\mathrm{e}}$ is the fatigue endurance limit, $\mathrm{n}$ is the safety factor, $S_{\mathrm{ut}}$ is the ultimate strength, and $\sigma_{m}$ and $\sigma_{a}$ are the mean and alternating stresses. Ghafoori et al. (2015a) showed that the modified Goodman criterion is conservative enough to prevent fatigue failure in ductile metals strengthened with CFRP laminates and can be used for design purposes.

\subsection{Effect of mean stress level}

Assume that a beam is subjected to cyclic loading and that the mean and alternating stresses at the beam bottom flange before strengthening are $\sigma_{m^{*}}$ and $\sigma_{a^{*}}$, as shown by point A in Figure 2. The beam will be then strengthened by pre-stressed NM CFRP laminates, and the mean stress will be shifted to $\sigma_{\mathrm{m} * *}$, while the stress amplitude will decrease only negligibly. The NM laminates due to their relatively smaller Young's modulus (compared to that of steel) often cannot decrease the alternating stress substantially. Path A-B in this figure shows the effect of the pre-stressed NM CFRP, by which the mean stress level can be considerably decreased but the stress amplitude is decreased only negligibly. Due to the applied compressive stress, the stress ratio is reduced from $R_{A}$ to $R_{B}$ (i.e., $R_{B}<R_{A}$ ). Point $B$ is in the safe zone, such that the metallic member will have an infinite fatigue life.

\subsection{Effect of alternating stress level (stress range)}

In this section, it is shown that it is also possible to increase the fatigue life of a metallic beam by increasing the stiffness of the metallic member using non-prestressed UHM CFRP laminates. By bonding the UHM CFRP laminates to the beam's bottom flange, the stiffness of the beam is increased. In this way, the minimum and the maximum stresses are reduced by a factor of $\alpha(\alpha>1)$. Therefore, the stress amplitude and the mean stress will also be reduced by the same factor, $\sigma_{a^{*}} / \alpha$ and $\sigma_{m^{*}} / \alpha$ as shown in Figure 2. In Figure 2, path A-C shows the stiffening effect. Point $C$ is in the safe zone, so this detail will have an infinite fatigue life under the applied cyclic loads. Note that stiffening can be accomplished in several ways, such as by increasing the thickness, the width or the Young's modulus of the CFRP laminate.

When the beam is strengthened by a pre-stressed UHM laminate, a combined effect of decreasing of both the mean and alternating stresses will be achieved. This is shown by point $\mathrm{D}$ in Figure 2. The shortcoming of this method is that UHM laminates are often brittle and difficult to use in pre-stressing solutions.

\section{CALCULATION OF RETROFIT \\ PARAMETERS TO AVOID FATIGUE CRACK}

Two methods for the fatigue strengthening of metallic beams were suggested in Section 2. In the first method, the NM CFRP is pre-stressed, and a compressive force is applied to the metallic member to reduce its fatigue vulnerability. In the second method, the stiffness of the metallic beam is increased such that the stresses are reduced below the fatigue limit. The main question about the first strengthening method is how much pre-stress should be applied to the CFRP laminate to achieve infinite fatigue life. For the second strengthening scheme, the main question is how stiff the CFRP laminates should be to reduce the stress to below the fatigue limit. To quantify the magnitude of the required CFRP pre-stress and Young's modulus in each of these methods, the behavior of the beams strengthened by the bonded pre-stressed CFRP laminates will be modeled in this section.

Consider a steel beam with a symmetrical crosssection that is strengthened by a pre-stressed CFRP laminate in the four-point bending set-up shown in Figure 3. The span length of the beam is L, and the length of the CFRP plate is $\mathrm{L}_{\mathrm{p}}$. The distance between the support to the end of the laminate is a, and the distance between the support to the concentrated load is b. Note that in Figure 3, the coordinate system is placed at the right end of the CFRP laminate; therefore, ' $\mathrm{x}$ ' indicates the longitudinal distance from the laminate end. Note that the subscripts ' $\mathrm{s}$ ' and ' $p$ ' denote terms related to the steel and the CFRP plate, respectively, and the superscripts $M$ and $\mathrm{N}$ are associated with the terms related to the bending and longitudinal forces at the neutral plane for each adherend, respectively. The governing differential equations of the laminated beam can be developed as described in Ghafoori (2015). Finally, the stress at the outermost fiber in the lower flange as function of $x$ can be written as (Ghafoori 2015)

$$
\begin{aligned}
& \sigma(x)=M_{T}(x) \frac{h}{2 I_{s}}-\frac{b_{p}}{\lambda^{2}}\left(\frac{h^{2}}{4 I_{s}}+\frac{1}{A_{s}}\right) . \\
& \left(\frac{d \tau(x)}{d x}+m_{1} \lambda^{2} M(x)+\frac{G_{a} N_{0}}{t_{a} E_{p} A_{p}}\right)
\end{aligned}
$$


where

$$
\lambda=\sqrt{\frac{G_{a} b_{p}}{t_{a}}\left(\frac{1}{E_{s} A_{s}}+\frac{1}{E_{p} A_{p}}+\frac{h^{2}}{4 E_{s} I_{s}}\right)}
$$

and

$$
m_{1}=\frac{G_{a}}{2 t_{a} \lambda^{2}} \frac{h}{E_{s} I_{s}}
$$

where $G_{a}$ is the shear modulus of the adhesive layer and $\mathrm{N}_{0}$ is the initial pre-stressing force in the laminate
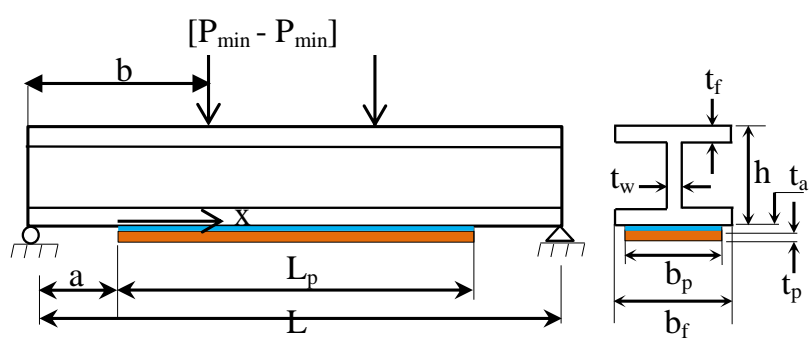

Figure 3. Scheme of a steel girder retrofitted by the bonded CFRP plate (Ghafoori 2015).

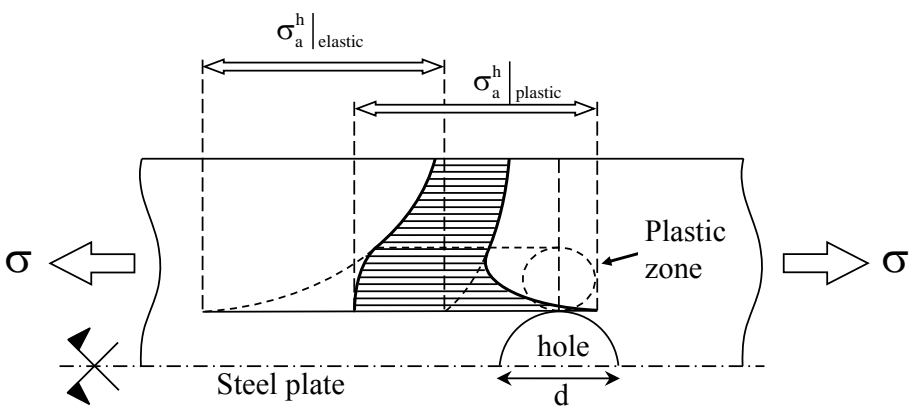

Figure 4. Scheme of stress distribution at the vicinity of a hole in a steel plate.

The method presented in the last section gives the stress at the beam bottom flange. The maximum bending moment, which is located at the beam midspan (i.e., $\left.\mathrm{x}=\mathrm{L}_{\mathrm{p}} / 2\right)$, is $\mathrm{M}_{\mathrm{t}}\left(\mathrm{L}_{\mathrm{p}} / 2\right)=\mathrm{Pa}$; thus, based on Equation (2), the stress at the beam bottom flange can be expressed by

$$
\begin{aligned}
& \sigma\left(L_{p} / 2\right)=\frac{h P a}{2 I_{s}}-b_{p}\left(\frac{h^{2}}{4 I_{s}}+\frac{1}{A_{s}}\right) \\
& \left(-\frac{\tau\left(L_{p} / 2\right)}{\lambda}+m_{1} P a+\frac{G_{a} N_{0}}{\lambda^{2} t_{a} E_{p} A_{p}}\right)=\sigma
\end{aligned}
$$

where $\tau\left(L_{p} / 2\right)$ is the interfacial shear stress at the beam's mid-span, which is zero in this case. For more details about development of Equation (5), the reader is referred to Ghafoori (2015). Assume that the strengthened beam is subjected to cyclic loading with minimum and maximum external load levels of $\mathrm{P}_{\min }$ and $\mathrm{P}_{\max }$, respectively, as shown in Figure 3. The maximum and the minimum stresses at the beam mid-span can be determined using Equation
(5). The mean and amplitude stresses at the beam bottom flange are expressed by

$$
\sigma_{\mathrm{m}}=\frac{h a P_{\mathrm{m}}}{2 I_{s}}-b_{p}\left(\frac{h^{2}}{4 I_{s}}+\frac{1}{A_{s}}\right)
$$

$\left(m_{1} a P_{\mathrm{m}}+\frac{G_{a} N_{0}}{\lambda^{2} t_{a} E_{p} A_{p}} e^{-\lambda L_{p} / 2}\right)$

and

$$
\begin{aligned}
& \sigma_{a}=\frac{h a P_{a}}{2 I_{s}}-b_{p}\left(\frac{h^{2}}{4 I_{s}}+\frac{1}{A_{s}}\right) \\
& \left(m_{1} a P_{a}+\frac{G_{a} N_{0}}{\lambda^{2} t_{a} E_{p} A_{p}}\right)
\end{aligned}
$$

where $\mathrm{P}_{\mathrm{a}}$ and $\mathrm{P}_{\mathrm{m}}$ are, respectively,

$$
P_{a}=\frac{P_{\max }-P_{\min }}{2}
$$

and

$$
P_{m}=\frac{P_{\max }+P_{\min }}{2}
$$

The magnitude of the stress at the edge of the hole is written by

$$
\sigma^{h}=k_{t o t} \sigma
$$

where $\mathrm{k}_{\mathrm{tot}}$ is given by

$$
k_{t o t}=k_{f} \frac{b_{f}}{b_{f}-d}
$$

In Equation (10), $d$ is the diameter of the hole (see Fig. 4) and $\mathrm{k}_{\mathrm{f}}$ is the fatigue stress concentration factor (SCF), which depends on the geometry and the material of the member and can be found by formulation given in Ghafoori et al. (2015a).

Figure 4 depicts the stress distribution of a notched plate under cyclic tension $(\mathrm{R}>0)$. With moderate loading the stresses remain in the elastic region, however, if the load increases, the peak stress exceeds the yield point and a plastic zone forms at the root of the notch during the first load cycle. This process lowers both the maximum stress and the minimum stress, which may even change to compression, at the hole while the stress amplitude does not change. Therefore, yielding can result in a decrease in the midrange stress level, which may a positive effect on the fatigue behavior. Nevertheless, service loads often apply low stress levels that are in elastic range, and, therefore, in this research, we assume an elastic material behavior.

For simplicity in design purposes, a conservative factor of $\mathrm{k}_{\mathrm{f}}=3$ can be approximated for fatigue SCF. Substitution of Equations (6) and (7) into Equation (10) yields the mean, $\sigma_{m}^{h}$, and the amplitude, $\sigma_{a}^{h}$, stresses at the location of the hole. The obtained mean and amplitude stresses are the critical stresses 
and are substituted into the Goodman criterion in Equation (1), which results in

$$
\begin{aligned}
& \frac{h a P_{a}}{2 I_{s} S_{e}}-\frac{b_{p}}{S_{e}}\left(\frac{h^{2}}{4 I_{s}}+\frac{1}{A_{s}}\right)\left(m_{1} a P_{a}+\frac{G_{a} N_{0}}{\lambda^{2} t_{a} E_{p} A_{p}}\right)+\frac{h a P_{\mathrm{m}}}{2 I_{s} S_{u t}} \\
& -\frac{b_{p}}{S_{u t}}\left(\frac{h^{2}}{4 I_{s}}+\frac{1}{A_{s}}\right)\left(+m_{1} a P_{\mathrm{m}}+\frac{G_{a} N_{0}}{\lambda^{2} t_{a} E_{p} A_{p}} e^{-\lambda L_{p} / 2}\right) \leq \frac{b_{p}-d}{n b_{p} k_{f}}
\end{aligned}
$$

Equation (11) can be solved in terms of different parameters such as pre-stress, $\mathrm{N}_{0}$, CFRP Young's modulus, $\mathrm{E}_{\mathrm{p}}$, laminate thickness, $\mathrm{t}_{\mathrm{p}}$, and laminate width, $b_{p}$. The solution gives the magnitude of the parameter to be used in the strengthening design, such that the stresses are shifted inside the fatigue safe region based on the Goodman criterion. Note that the equality form of Equation (11) gives the minimum magnitude of the design parameter, whereas the inequality form of Equation (11) gives a range for the magnitude of the design parameter that can shift the stresses inside the safe zone (i.e., blue region in Fig. 2).

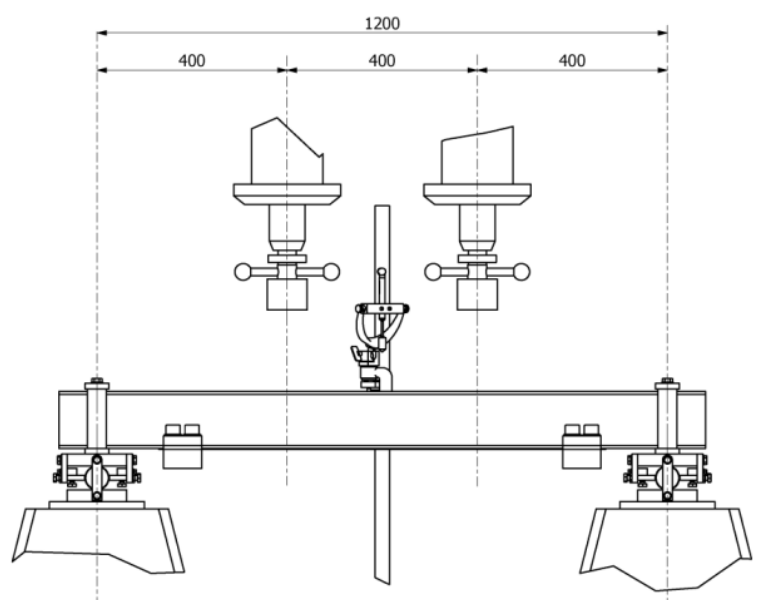

(a)

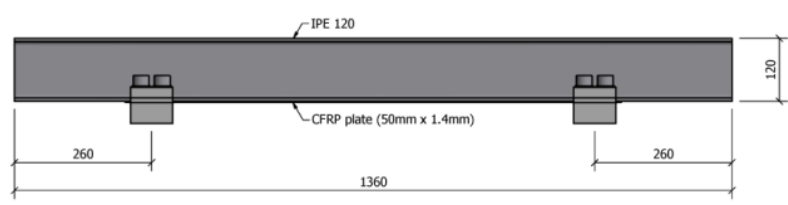

(b)

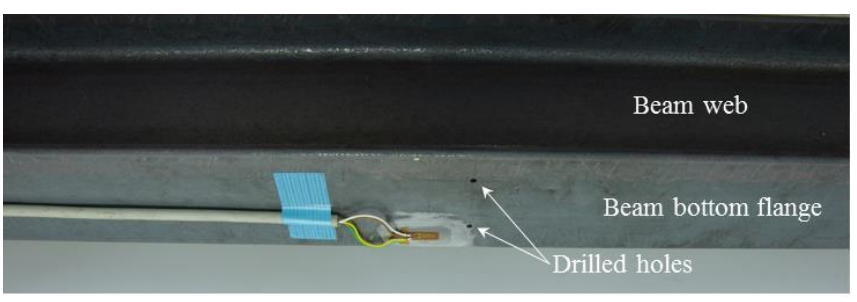

(c)

Figure 5. (a) Fatigue test set-up (dimensions in $\mathrm{mm}$ ), (b) retrofitted specimen, (c) holes drilled in beam bottom flange.

Note that the method described in this paper is only to prevent fatigue crack initiation. However, if bridge members have already cracks (prior to strengthening), a fracture mechanics based model that has been proposed previously by the authors (Ghafoori and Motavalli 2011, Ghafoori et al. 2012a, Ghafoori et al. 2012b) can be used to determine the required CFRP pre-stressing level needed to arrest the fatigue crack propagation in the metal. Non-destructive testing (NDT) inspections can provide evidences of the state of bridge elements, and help bridge authorities to choose the right strengthening scheme. Note that the presented method in this paper can be also applied for fatigue retrofitting of metallic (e.g., steel, wrought and cast irons) plates. Furthermore, the retrofit elements can be other than CFRP composites such as steel or aluminum plates.

\section{FATIGUE TEST SET-UP AND SPECIMENS}

Four specimens were prepared and strengthened with non-prestressed CFRP laminates with different Young's moduli of $159 \mathrm{GPa}(\mathrm{NM}), 220 \mathrm{GPa}$ (HM) and $440 \mathrm{GPa}$ (UHM). All beams were tested in a four-point bending set-up with a loading span of $\mathrm{L}=1,200 \mathrm{~mm}$, a shear span of $\mathrm{b}=400 \mathrm{~mm}$ and $\mathrm{a}$ CFRP laminate length of $L_{p}=920 \mathrm{~mm}$ (i.e., $a=140$ $\mathrm{mm})$. The material and the geometric properties of the steel beams, the CFRP laminate and the adhesive layer are described based on notations in Figure 3 as follows: $\mathrm{b}_{\mathrm{f}}=65 \mathrm{~mm}, \mathrm{t}_{\mathrm{f}}=6.2 \mathrm{~mm}, \mathrm{t}_{\mathrm{w}}=4.4 \mathrm{~mm}, \mathrm{~h}=120$ $\mathrm{mm}, \mathrm{t}_{\mathrm{p}}=1.4 \mathrm{~mm}, \mathrm{~b}_{\mathrm{p}}=50 \mathrm{~mm}, \mathrm{t}_{\mathrm{a}}=1 \mathrm{~mm}, \mathrm{E}_{\mathrm{s}}=199.3 \mathrm{GPa}$ and $\mathrm{G}_{\mathrm{a}}=1,040 \mathrm{MPa}$. The Young's modulus of the NM, HM and UHM laminates are $E_{p}^{N M}=159 \mathrm{GPa}$, $E_{p}^{H M}=220 \mathrm{GPa}$ and $E_{p}^{U H M}=440 \mathrm{GPa}$.

All beams were tested using the symmetric fourpoint bending set-up shown in Figure 5.a. For all of the fatigue tests, a loading frequency of $4.35 \mathrm{~Hz}$ was maintained. Steel beams were retrofitted by CFRP laminates, as shown in Figure 5.b. Figure 5.c shows the state of two small holes, each with a diameter of $3 \mathrm{~mm}$, which were drilled on bottom flange at midspan to create stress concentrations to initiate fatigue cracks while also simulating the effect of rivet holes in riveted bridges. Special attention was paid during the drilling of the holes, and quality control was ensured using non-destructive testing (NDT) methods to verify the surface condition of the holes between specimens. For all fatigue strengthened specimens, three strain gauges were glued on the laminate, one at the symmetry line, and two at distances of 200 $\mathrm{mm}$ and $300 \mathrm{~mm}$ from the symmetry line. One additional strain gauge was applied on the beam's bottom flange. By using the method presented in Ghafoori et al. (2015a), the fatigue SCF for each hole at the beam bottom flange is found to be $\mathrm{k}_{\mathrm{f}}=2.35$. From Equation (10), the total SCF is calculated to be $\mathrm{k}_{\mathrm{tot}}=2.59$.

The endurance limit was also determined by using Marin's method described in Ghafoori et al. (2015a) to be $S_{\mathrm{e}}=220 \mathrm{MPa}$. By having $\mathrm{S}_{\mathrm{y}}$ and $\mathrm{S}_{\mathrm{e}}$, Figure 6 
can be drawn. All specimens were subjected to an elastic cyclic loading range of $\mathrm{P}=[1.7-18] \mathrm{kN}$.

\section{RESULTS}

First, the unstrengthened reference specimen, B0, was subjected to a cyclic loading. The fatigue loading was stopped in intervals of approximately $10 \mathrm{k}$ cycles for an NDT inspection. The Eddy Current NDT system was used to inspect the area near the hole region to detect the formation of any cracks. The Eddy Current system works based on the electromagnetic induction of circular coils and is often used to find flaws down $0.5 \mathrm{~mm}$ in conductive metals.

Table 1. Fatigue test results.

\begin{tabular}{|c|c|c|c|c|}
\hline $\begin{array}{c}\text { Speci- } \\
\text { men }\end{array}$ & $\begin{array}{c}\text { Retrofit } \\
\text { scheme }\end{array}$ & $\begin{array}{c}\text { CFRP } \\
\text { type }\end{array}$ & $\begin{array}{c}\text { Cycles to } \\
\text { failure }\end{array}$ & Failure mode \\
\hline B0 & Reference & - & $448 \mathrm{k}$ & Cracked \\
\hline B1 & Bonded & NM & $1,705 \mathrm{k}$ & Cracked \\
\hline B2 & Bonded & HM & $2,000 \mathrm{k}$ & Runout \\
\hline B3 & Bonded & UHM & $2,000 \mathrm{k}$ & Runout \\
\hline
\end{tabular}

A fatigue crack was initiated from the hole at the beam bottom flange after 448,000 cycles. Note that the main goal of this study is to prevent fatigue crack initiation; thus, as soon as a crack was detected, the specimen was considered to have failed.

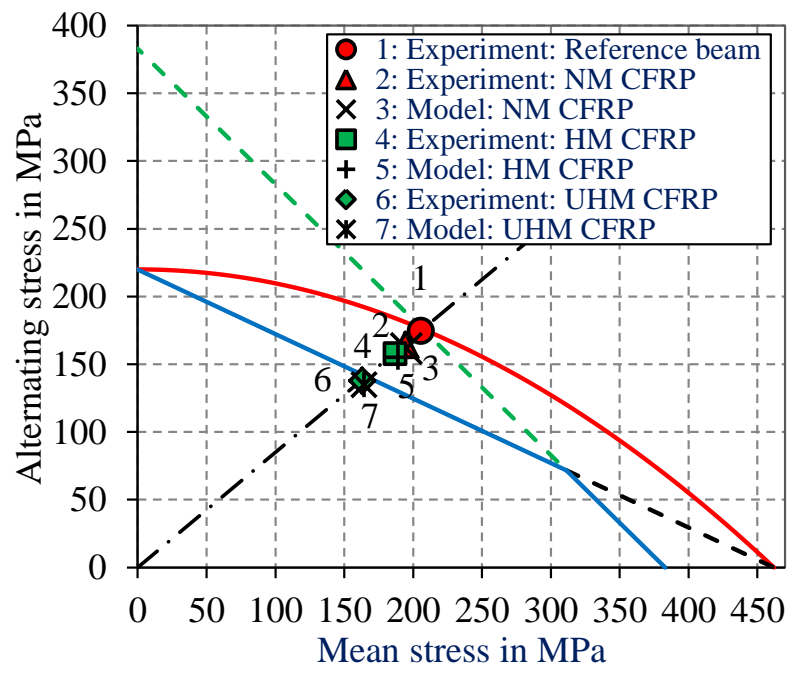

Figure 6. Test results show that as the CFRP Young's modulus increases, the stresses approach the safe zone along the original stress ratio line. This figure compares the experimental and modeling results.

Specimen B1 was strengthened using the NM CFRP laminate and was then subjected to cyclic loading. The fatigue crack initiated from the hole after $1,705,000$ cycles. Similar to the reference specimen, the crack first propagated in the bottom flange and later into the web. Due to the high interfacial shear stresses at the adhesive layer near the damaged section (i.e., at $\mathrm{x}=\mathrm{L}_{\mathrm{p}} / 2$ ), CFRP-to-steel debonding occurred at the middle of the CFRP laminate and propagated towards the laminate ends. After the CFRP laminate was debonded, the overall SIF at the crack tip exceeded the mode-I fracture toughness of steel and a sudden failure occurred.

Different fracture failure stages for the reference specimen, B0, are shown in Figure 7.a. Stage 1 depicts the crack initiation phase, in which microcracks are nucleated from the hole (see Fig. 7.b). Because of the influence of microstructures (e.g., grain boundaries) in stage 1, the propagation of $\mathrm{mi}$ crocracks can be erratic and very slow. Nonetheless, after some further microcrack growth away from the nucleation site, a more regular crack growth will occur, which is the commencement of the macrocrack fatigue crack propagation. Note that although crack growth occurs in both stages 1 and 2, differentiating between these two stages is very important because the parameters that are affecting each stage are different. For example, surface conditions have a significant influence on the initiation phase (stage 1); however, they have negligible effects on the crack growth phase (stage 2). Eventually, a sudden "brittle" failure of the structural element occurs in the steel section. Note that the main aim of the method presented in this paper is to develop a method to increase the duration of the crack initiation stage (i.e., stage 1) to infinity by reducing the applied stresses below the material fatigue limit.

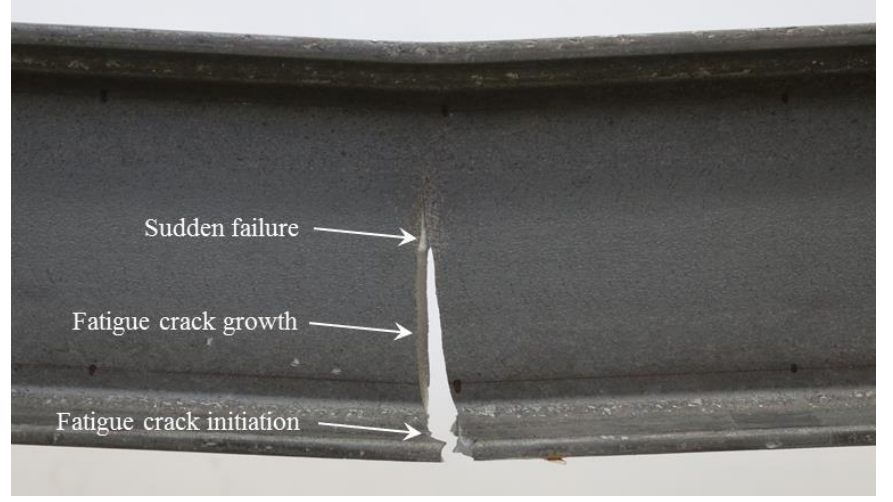

(a)

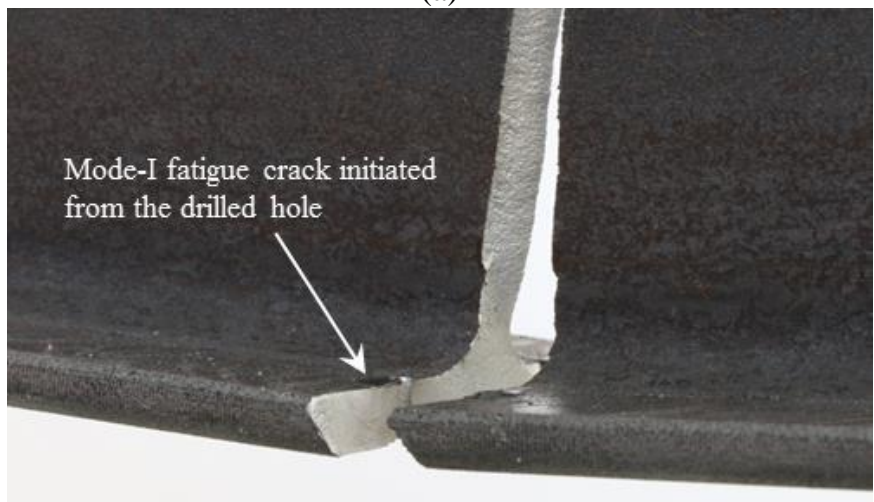

(b)

Figure 7.a. (a) Different stages of fracture failures observed in the reference specimen $\mathrm{B} 0$ : crack initiation, crack propagation and a sudden fracture failure, (b) crack emanated from stress concentration location.

For retrofitted specimen B1 crack initiated from the hole and propagated into the steel web, as shown in Figure 8.a. Because of high interfacial shear stress at the adhesive layer under the cracked section, CFRP debonded from the beam bottom flange, as 
shown in Figure 8.b, and, suddenly a rapid fracture failure in steel web occurred.

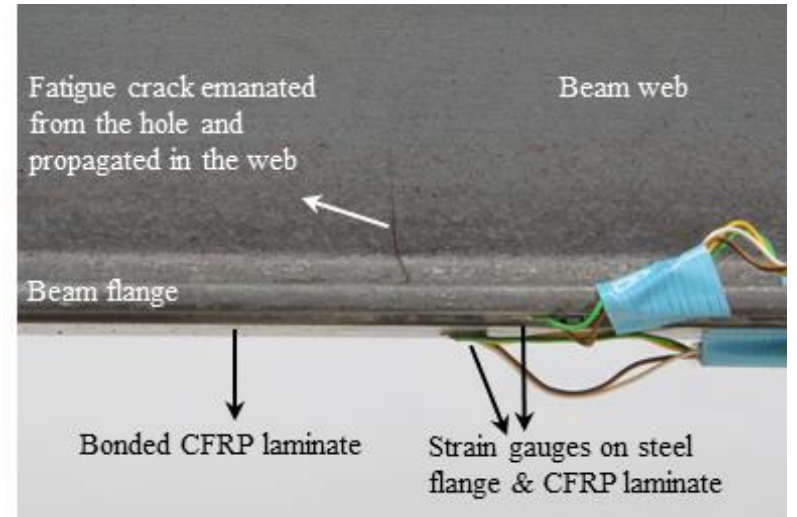

(a)

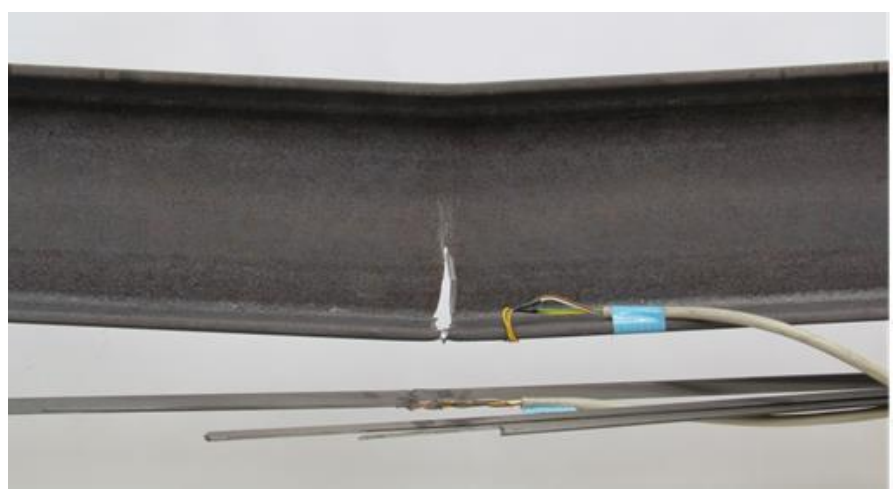

(b)

Figure 8. (a) fatigue crack initiated from the hole of the retrofitted specimen B1 and propagated into the steel web, (b) CFRP debonding occurred because of high interfacial shear stress at the CFRP-to-steel adhesive joint under the cracked section. A sudden fracture failure in steel web occurred after the CFRP debonding.

Specimen B2 was strengthened using the HM laminate and was then subjected to cyclic loading. The specimen survived more than 2,000,000 cycles and no crack was detected (using the Eddy current system) near the holes in the bottom flange. Furthermore, specimen B3 was strengthened using the UHM laminate and was subjected to cyclic loading. The specimen survived more than 2,000,000 cycles and no crack was found at the location of the holes.

Table 1 shows the number of cycles applied to each specimen and the corresponding failure mode. Figure 6 shows the stresses in the reference specimen and in the specimens strengthened by the NM, the HM and the UHM CFRP laminates in the CLD. The results from the experiments are compared with those obtained from the presented analytical model. It is seen that as the stiffness of the laminate increases, the stresses approach the safe region along the stress ratio line $\mathrm{R}=0.09$, which verifies the assumption made in the presented model. In Figure 6, the red markers represent the failed specimens, whereas the green markers indicate the survivors after $2,000,000$ cycles. Note that the number 2,000,000 was assumed to be the run-out number of cycles according to the concept of fatigue threshold for steels.

\section{CONCLUSIONS}

Two main mechanisms that shift the detail from the risky finite-life regime to the safe infinite-life regime were identified: Mechanism 1: by applying a prestress force to an existing fatigue-susceptible detail, the mean stress level and the stress ratio, R, will be reduced such that the detail is shifted from the finitelife regime to the infinite-life regime. Mechanism 2: by increasing the stiffness of the beam (e.g., by using the UHM CFRP laminates), the stress ratio, $\mathrm{R}$, is preserved, but the mean and alternating stresses will be reduced such that the detail is shifted from the finite-life regime to the infinite-life regime.

It was shown that bonded UHM CFRP laminates are efficient to prevent fatigue crack initiation in steel structures. The presented method can determine the required CFRP pre-stress and/or the CFRP Young's modulus based on the stress history from the current traffic loadings on the bridge, to prevent future fatigue crack initiation. The proposed retrofit approach can be used particularly for the fatigue strengthening of metallic structures with unknown stress history from past traffic loadings.

\section{ACKNOWLEDGMENTS}

This research was mainly funded by the Swiss Commission of Technology and Innovation (CTI) (No. 12993.1 PFIW-IW). The authors would also like to thank Mr. Tobias Humbel and the technicians of the Structural Engineering Research Laboratory of Empa for their excellent cooperation in performing the experiments. The authors gratefully acknowledge the support from the Epsilon Composite Company, France, and the S\&P Clever Reinforcement Company AG, Switzerland, for providing the materials for this study. Support from the Australian Research Council Linkage Grant (No. LP140100543) is also appreciated.

\section{REFERENCES}

Akesson, B. 1994. Fatigue life of riveted railway bridges. $\mathrm{PhD}$ Thesis, Chalmers University of Technology, Sweden.

Al-Emrani, M. \& Kliger, R. 2006. Analysis of interfacial shear stresses in beams strengthened with bonded prestressed laminates. Composites - Part B, 37, 265272.

Budynas, R. G. \& Nisbett, J. K. 2008. Shigley's Mechanical Engineering Design, New York, McGraw-Hill.

Colombi, P., Bassetti, A. \& Nussbaumer, A. 2003a. Analysis of cracked steel members reinforced by pre-stress composite patch. Fatigue and Fracture of Engineering Materials and Structures, 26, 59-66.

Colombi, P., Bassetti, A. \& Nussbaumer, A. 2003b. Crack growth induced delamination on steel members reinforced by prestressed composite patch. Fatigue Fract Engng Mater Struct, 26, 429-437.

Dawood, M., Rizkalla, S. \& Sumner, E. 2007. Fatigue and overloading behavior of steel-concrete composite 
flexural members strengthened with high modulus CFRP materials. Journal of Composites for Construction, 11, 659-669.

Deng, J., Lee, M. M. K. \& Moy, S. S. J. 2004. Stress analysis of steel beams reinforced with a bonded CFRP plate. Composite Structures, 65, 205-215.

Denton, S. Y. 12-14, December 2001. Analysis of stresses developed in FRP plated beams due to thermal effects. Proceedings of the Conference on Composites in Civil Engineering, Hong Kong, P:527-36.

El-Hacha, R. \& Aly, M. Y. E. 2013. Anchorage system to prestress FRP laminates for flexural strengthening of steel-concrete composite girders. Journal of Composites for Construction, 17, 324-335.

Ghafoori, E. 2013. Interfacial stresses in beams strengthened with bonded prestressed plates. Engineering Structures, 46, 508-510.

Ghafoori, E. 2015. Fatigue strengthening of metallic members using un-bonded and bonded CFRP laminates. PhD Thesis, ETH-Zurich, http://dx.doi.org/10.3929/ethz-a010453130 .

Ghafoori, E. \& Motavalli, M. 2011. Analytical calculation of stress intensity factor of cracked steel I-beams with experimental analysis and 3D digital image correlation measurements. Engineering Fracture Mechanics, 78, 3226-3242.

Ghafoori, E. \& Motavalli, M. 2013. Flexural and interfacial behavior of metallic beams strengthened by prestressed bonded plates. Composite Structures, 101, 22-34.

Ghafoori, E. \& Motavalli, M. 2015a. Innovative CFRP Prestressing System for Strengthening of Metallic Structures. Journal of Composites for Construction, doi: $\quad$ http://dx.doi.org/10.1061/(ASCE)CC.1943$\underline{5614} .0000559$.

Ghafoori, E. \& Motavalli, M. 2015b. Lateral-torsional buckling of steel I-beams retrofitted by bonded and un-bonded CFRP laminates with different pre-stress levels: experimental and numerical study. Construction and Building Materials, 76, 194-206.

Ghafoori, E. \& Motavalli, M. 2015c. Normal, high and ultrahigh modulus CFRP laminates for bonded and unbonded strengthening of steel beams. Materials and Design, 67, 232-243.

Ghafoori, E., Motavalli, M., Botsis, J., Herwig, A. \& Galli, M. 2012a. Fatigue strengthening of damaged metallic beams using prestressed unbonded and bonded CFRP plates. International Journal of Fatigue, 44, 303-315.

Ghafoori, E., Motavalli, M., Nussbaumer, A., Herwig, A., Prinz, G. \& Fontana, M. 2015a. Determination of minimum CFRP pre-stress levels for fatigue crack prevention in retrofitted metallic beams. Engineering Structures, 84, 29-41.

Ghafoori, E., Motavalli, M., Nussbaumer, A., Herwig, A., Prinz, G. S. \& Fontana, M. 2015b. Design criterion for fatigue strengthening of riveted beams in a 120 -yearold railway metallic bridge using pre-stressed CFRP plates. Composites Part B, 68, 1-13.

Ghafoori, E., Motavalli, M., Zhao, X. L., Nussbaumer, A. \& Fontana, M. 2015c. Fatigue design criteria for strengthening metallic beams with bonded CFRP plates. Engineering Structures, 101, 542-557.

Ghafoori, E., Prinz, G. S., Mayor, E., Nussbaumer, A., Motavalli, M., Herwig, A. \& Fontana, M. 2014. Finite element analysis for fatigue damage reduction in metallic riveted bridges using pre-stressed CFRP plates. Polymers, 6, 1096-1118.

Ghafoori, E., Schumacher, A. \& Motavalli, M. 2012b. Fatigue behavior of notched steel beams reinforced with bonded CFRP plates: Determination of prestressing level for crack arrest. Engineering Structures, 45, 270283.

Haghani, R., Al-Emrani, M. \& Kliger, R. 2009. Interfacial stress analysis of geometrically modified adhesive joints in steel beams strengthened with FRP laminates. Construction and Building Materials, 23, 1413-1422.

Kim, Y. J. \& Harries, K. A. 2011. Fatigue behavior of damaged steel beams repaired with CFRP strips. Engineering Structures, 33, 1491-1502.

Nozaka, K., Shield, C. \& Hajjar, J. 2005. Effective Bond Length of Carbon-Fiber-Reinforced Polymer Strips Bonded to Fatigued Steel Bridge I-Girders. Journal of Bridge Engineering, 10, 195-205.

Rizkalla, S., Dawood, M. \& Schnerch, D. 2008. Development of a carbon fiber reinforced polymer system for strengthening steel structures. Composites - Part A, 39, 388-397.

Saadatmanesh, H., Albrecht, P. \& Ayyub, B. M. 1989. Guidelines for flexural design of prestressed composite beams. Journal of structural engineering New York, N.Y., 115, 2944-2961.

Schnerch, D., Dawood, M., Rizkalla, S., Sumner, E. \& Stanford, K. 2006. Bond behavior of CFRP strengthened steel structures. Advances in Structural Engineering, 9, 805-817.

Schnerch, D. \& Rizkalla, S. 2008. Flexural Strengthening of Steel Bridges with High Modulus CFRP Strips. Journal of Bridge Engineering, 13, 192-201.

Täljsten, B., Hansen, C. S. \& Schmidt, J. W. 2009. Strengthening of old metallic structures in fatigue with prestressed and non-prestressed CFRP laminates. Construction and Building Materials, 23, 1665-1677.

Tavakkolizadeh, M. \& Saadatmanesh, H. 2003. Fatigue Strength of Steel Girders Strengthened with Carbon Fiber Reinforced Polymer Patch. Journal of structural engineering, 129, 186-196.

Wu, C., Zhao, X. L., Al-Mahaidi, R., Emdad, M. R. \& Duan, W. H. 2013a. Fatigue tests on steel plates with longitudinal weld attachment strengthened by ultra high modulus carbon fibre reinforced polymer plate. Fatigue and Fracture of Engineering Materials and Structures, 36, 1027-1038.

Wu, C., Zhao, X. L., Chiu, W. K., Al-Mahaidi, R. \& Duan, W. H. 2013b. Effect of fatigue loading on the bond behaviour between UHM CFRP plates and steel plates. Composites Part B: Engineering, 50, 344-353.

Zhao, X. L. 2013. FRP-Strengthened Metallic Structures, Boca Raton, FL, Taylor and Francis.

Zhao, X. L., Bai, Y., Al-Mahaidi, R. \& Rizkalla, S. 2014. Effect of dynamic loading and environmental conditions on the bond between cfrp and steel: Stateof-the-art review. Journal of Composites for Construction, 18.

Zhao, X. L. \& Zhang, L. 2007. State-of-the-art review on FRP strengthened steel structures. Engineering Structures, 29, 1808-1823. 